\title{
Biosynthesis of Silver Nanoparticles using Olea europaea Leaves Extract and its Antibacterial Activity
}

\author{
Akl M. Awwad ${ }^{1, *}$, Nidà M. Salem², Amany O. Abdeen ${ }^{1}$ \\ ${ }^{1}$ Royal Scientific Society, Princess Sumaya University for Technology, El Hassan Science City, Amman, Jordan \\ ${ }^{2}$ Plant Protection Department, Faculty of Agriculture, University of Jordan, Amman Jordan
}

\begin{abstract}
This paper reports a rapid and ecofriendly green method for the synthesis of silver nonoparticles from silver nitrate solution using Olea europaea leaves extract. Effect of Olea europaea leaves extract, silver nitrate concentration, reaction time and temperature on reaction rate were investigated. The synthesized silver nanoparticles (AgNPS) were characterized with scanning electron microscopy (SEM), X-ray diffraction (XRD), atomic absorption spectroscopy (AAS) and fourier infrared spectroscopy (FT-IR). UV-vis spectra gave surface plasmon resonance (SPR) at $430 \mathrm{~nm}$. This reveals the reduction of silver ions $\left(\mathrm{Ag}^{+}\right)$to silver $\left(\mathrm{Ag}^{\mathrm{o}}\right)$ which indicates the formation of silver nanoparticles (AgNPs). The antibacterial activity of green synthesized AgNPs showed effective inhibitory activity against water borne pathogens Listeria monocytogenes, Shigella and Staphylococcus aureus. This reveals that silver nanoparticles could provide a safer alternative to conventional antimicrobial and antibacterial agents.
\end{abstract}

Keywords Silver Nanoparticles, Olea europaea Leaves Extract, Biosynthesis, Characterization, Antibacterial Activity

\section{Introduction}

The development of green methods for the synthesis of nanoparticles is evolving into an important branch of nanotechnology, because these methods are considered safe and ecologically sound the nanomaterials fabrication as an alternative to conventional methods[1-6]. The green synthesis techniques are generally synthetic routes that utilize relatively nontoxic solvents such as water, biological extracts, biological systems and microwave assisted synthesis. Silver nanoparticles (AgNPs) have become the focus of intensive research owing to their wide range of application in the development of new techniques in the areas of electronics, medicine, materials sciences due to good conductivity and chemical stability, selective coatings of solar energy absorption, intercalation materials for electrical batteries, optical receptors, catalysts in chemical reactions, bio labeling, optoelectronics, medical devices, antibacterial and biomaterials production. Many research works are available on the biosynthesis of silver nanoparticles using plant leaves extract, such as Ficus benghalensis[7], Rosa rugosa[8], Stevia rebaudiana[9], Chenopodium album[10], Nicotiana tobaccum[11], Trianthema de candra[12], Polyalthia longifolia[13], Cycas[14], Pinus desiflora, Diopyros kaki, Ginko biloba, Magnolia kobus, and Pllatanus orientalis[15],

* Corresponding author:

amawwad2000@yahoo.com (Ak1 M. Awwad)

Published online at http://journal.sapub.org/nn

Copyright (C) 2012 Scientific \& Academic Publishing. All Rights Reserved
Catharanthus roseus[16], Pungamia pinnata, Hemidesmus indicus, Syzygium cumini, Allium cepa, and Pandaanus odorifer[17], Sesuvium portulacastrum L[18], Acalypha indica[19], Parthenium hysterophorous[20], Capsicum annuиm[21], Piper longum[22], Arbutus unedo[23], Ocimum santum[24], and mullberry[25]. On the basis of available scientific literature, this study was designed with a simple, rapid, cost-effective and environmentally synthesis method of silver nanoparticles at ambient conditions using Olea europaea leaves extract.

\section{Materials and Methods}

Silver nitrate $\left(\mathrm{AgNO}_{3}\right)$ was obtained from Aldrich Chemicals. All glassware have been washed with sterile distilled water and dried in an oven before use.

\subsection{Preparation of Olea Europaea Leaves Extract}

Freshly leaves of Olea europaea, Figure 1 were collected from olive trees at Royal Scientific Society, Amman, Jordan. Olea europaea leaves were washed several times with water to remove the dust particles and then sun dried to remove the residual moisture. The extract used for the reduction of silver ions $\left(\mathrm{Ag}^{+}\right)$to silver nanoparticles $\left(\mathrm{Ag}^{0}\right)$ was prepared by placing $50 \mathrm{~g}$ of washed dried fine cut leaves in $1 \mathrm{~L}$ glass beaker along with $500 \mathrm{~mL}$ of sterile distilled water. The mixture was then boiled for 10 minutes until the color of the aqueous solution changes from watery to light yellow. Then the extract was cooled to room temperature and filtered with Whatman No. 1 filter paper. Filtrate was collected and stored 
at room temperature in order to be used for further experiments.

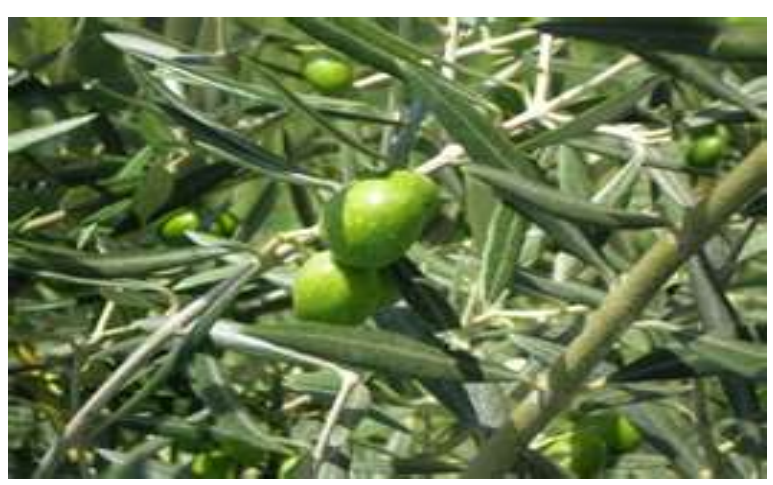

Figure 1. Picture of Olea europaea leaves

\subsection{Synthesis of Silver Nanoparticles}

$5 \mathrm{~mL}$ of Olea europaea leaves extract was added with stirring to $100 \mathrm{~mL}$ of $10^{-3} \mathrm{M}$ aqueous solution of silver nitrate $\left(\mathrm{AgNO}_{3}\right)$ in $250 \mathrm{~mL}$ flask to give a pale yellow solution mixture at room temperature. The mixture was heated in a water bath at at $\left(30-80^{\circ} \mathrm{C}\right)$. We observed that the color of the solution mixture of silver nitrate and Olea europaea leaves extract changed from pale yellow color to deep yellow color at $40^{\circ} \mathrm{C}$ and $5 \mathrm{~min}$ of reaction time. Increasing the temperature of water bath to $60^{\circ} \mathrm{C}$ and 10 min of reaction time, the color of mixture was changed to deep brown color and at $15 \mathrm{~min}$ of reaction time at $60^{\circ} \mathrm{C}$ the deep brown color was changed to grey-black due to excitation of surface plasmon. This indicates the reduction of $\mathrm{Ag}^{+}$ions to $\mathrm{Ag}^{\mathrm{o}}$ nanoparticles. This indicates that as the temperature of the reaction increases the reaction is faster. The concentrations of $\mathrm{AgNO}_{3}$ solution and Olea europaea leaves extract were also varied at $1-4 \mathrm{mM}$ and $5-20 \%$ by volume, respectively. The silver nanoparticles (AgNPs) obtained by Olea europaea leaves extract were centrifuged at $15,000 \mathrm{rpm}$ for $10 \mathrm{~min}$ and subsequently redisposed in sterile distilled water to get rid of any uncoordinated biological materials.

\subsection{Characterization of Silver Nanoparticles}

UV-vis Spectroscopy

The optical property of biosynthesized silver nanoparticles samples were measured at room temperature by UV-vis spectrophotometer (Shimadzu UV-1601) operated at a resolution of $1 \mathrm{~nm}$ between 200 and $800 \mathrm{~nm}$ range.

X-ray diffraction measurements (XRD)

Crystalline metallic silver nanoparticles were examined by X-ray diffractometer (Shimadzu (XRD-6000) equipped with $\mathrm{Cu} \mathrm{K}(\alpha)$ radiation of $1.54187 \mathrm{~nm}$ wavelength, using $\mathrm{Ni}$ as filter and at a setting of $30 \mathrm{kV} / 30 \mathrm{~mA}$. All XRD data were collected under the same experimental conditions, in the angular range $3^{\circ} \leq 2 \theta \leq 50^{\circ}$.

Fourier transform infrared spectroscopy (FT-IR)

FT-IR for olive leaves extract powder was obtained in the range 4000-400 $\mathrm{cm}^{-1}$ with IR-Prestige-21 Shimaduz FTIR spectrophotometer, using $\mathrm{KBr}$ pellet method.

Transmission electron microscopy (SEM)

Scanning electron microscopy (SEM) analysis of silver nanoparticles was done using Hitachi S-4500 SEM machine. Thin films of the silver nanoparticles were prepared on a carbon coated copper grid by just droping a very small amount of the sample on the grid, extra solution was removed using a blotting paper and then the film on the SEM grid were allowed to dry by putting it under a mercury lamp for 5 minutes.

Atomic absorption spectroscopy (AAS)

Analysis of the conversion of silver nitrate into silver nanoparticles at various reaction times was analyzed with atomic absorption spectrometer (AAS6300 Shimadzu,).

\subsection{Antibacterial Studies}

Antibacterial activities of the biosynthesized silver nanoparticles against Listeria monocytogenes, Shigella and Staphylococcus aureus were determined using the agar diffusion assay method[26]. Aqueous dispersions of silver nanoparticles of various concentrations 10, 50, 100 and 200 $\mu \mathrm{g} / \mathrm{mL}$ were made. Stock culture of Listeria monocytogenes, Shigella and Staphylococcus aureus were grown separately in liquid nutrient broth medium. Silver nitrate $\left(\mathrm{AgNO}_{3}\right)$ was taken as a control. The plates were examined for evidence of zones of inhibition, which appeared as a clear area around the wells. The diameter of such zones of inhibition was measured using a meter ruler and the mean value for each organism was recorded and expressed in millimeter.

\section{Results and Discussion}

\subsection{FT-IR spectrum of Olea Europaea Leaves Extract}

To investigate the functional groups of Olea europaea leaves extract, a FT-IR study was carried out and the spectra are shown in Figure 2. The olive leaves extract displays a number of absorption peaks, reflecting its complex nature. A peak at $3367 \mathrm{~cm}^{-1}$ results due to the stretching of the $\mathrm{N}-\mathrm{H}$ bond of amino groups and indicative of bonded hydroxyl (-OH) group. The strong absorption peak at $2936 \mathrm{~cm}^{-1}$ could be assigned to $-\mathrm{CH}$ stretching vibrations of $-\mathrm{CH}_{3}$ and $-\mathrm{CH}_{2}$ functional groups. The shoulder peak at $1735 \mathrm{~cm}^{-1}$ assigned for $\mathrm{C}=\mathrm{O}$ group of carboxylic acids. The peak at $1654 \mathrm{~cm}^{-1}$ indicates the fingerprint region of $\mathrm{CO}, \mathrm{C}-\mathrm{O}$ and $\mathrm{O}-\mathrm{H}$ groups, which exists as functional groups of olive leaves extract. The absorption peaks at $1654 \mathrm{~cm}^{-1}$ could be attributed to the presence of $\mathrm{C}-\mathrm{O}$ stretching in carboxyl coupled to the amide linkage in amide I. The band at $1531 \mathrm{~cm}^{-1}$ is characteristic of amide II arises as a result of the N-H stretching modes of vibration in the amide linkage. The band at $1462 \mathrm{~cm}^{-1}$ assigned to the methylene scissoring vibrations from the proteins. The intense band at $1083 \mathrm{~cm}^{-1}$ can be assigned to the $\mathrm{C}-\mathrm{N}$ stretching vibrations of aliphatic amines. FTIR study of the Olea europaea leaves extract indicates that the carboxyl $(-\mathrm{C}=\mathrm{O})$, hydroxyl $(-\mathrm{OH})$ and amine $(\mathrm{N}-\mathrm{H})$ groups of Olea europaea leaves extract are mainly involved in 
reduction of $\mathrm{Ag}^{+}$to $\mathrm{Ag}^{\mathrm{o}}$ nanoparticles.

\subsection{Visual observation and UV-vis spectral study}

Formation and stability of AgNPs in sterile distilled water is confirmed with UV-vis spectrophotometer in a range of wavelength from 200 to $800 \mathrm{~nm}$. As soon as, Olea europaea leaves extract was mixed in aqueous solution of silver ions, the reduction of pure $\mathrm{Ag}^{+}$ions to $\mathrm{Ag}^{0}$ was monitored by measuring UV-vis spectrum of the reaction media at regular intervals, Figure 3. The addition of Olea europaea leaves extract to silver nitrate solution resulted in color change of the solution from transparent to yellow, Uv-vis spectra showed no peak and no sign for the synthesis of silver nanoparticles at zero time. At $5 \mathrm{~min}$ of the reaction time, the color changed from yellow to brown because of the excitation of surface plasmon vibrations with the silver nanoparticles. The surface plasmon resonance (SPR) of silver nanoparticles produced a peak centered near $430 \mathrm{~nm}$. UV- vis absorbance of reaction mixture was taken from 0 till $10 \mathrm{~min}$, Figure 3. It was also observed that bioreduction of silver ions into nanoparticles started at 5 min of reaction and was completed at almost $10 \mathrm{~min}$ indicating rapid biosynthesis of silver nanoparticles.

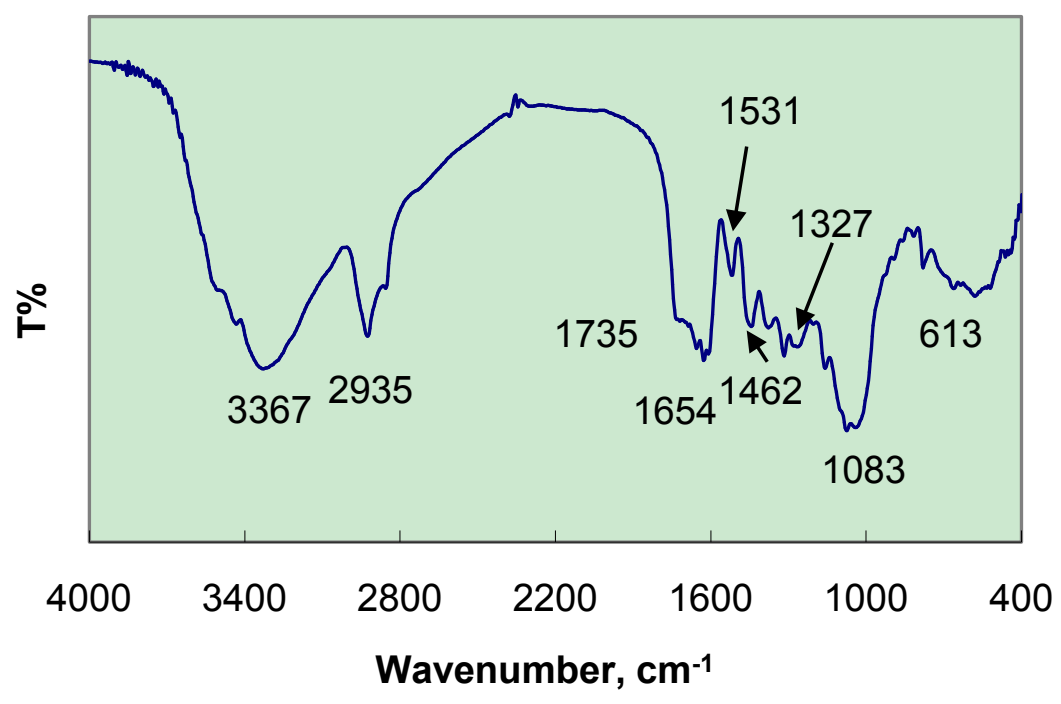

Figure 2. FT-IR spectra of Olea europaea leaves extract powder

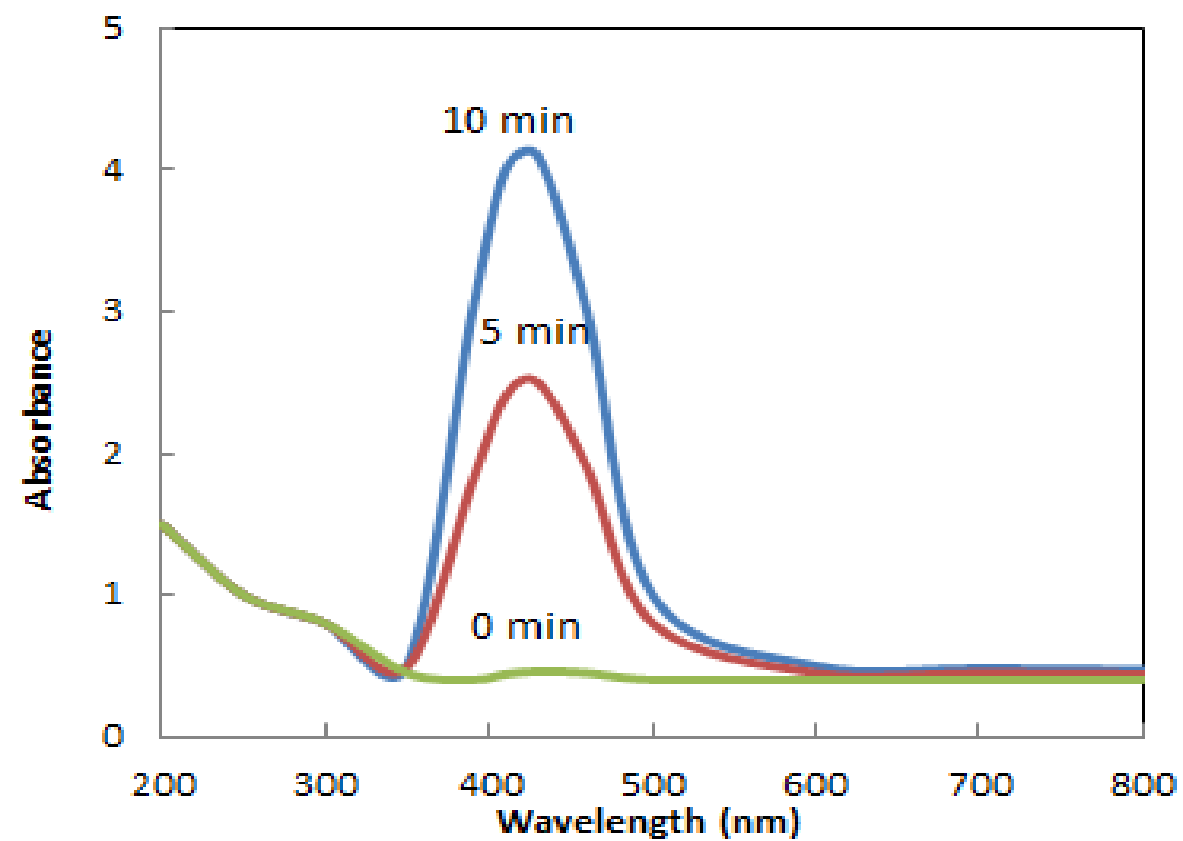

Figure 3. UV-vis spectra showing absorption of $10^{-3} \mathrm{M}$ aqueous solution of silver nitrate with Olea europaea leaves extract as a function of time 


\subsection{X-ray diffraction (XRD) Studies}

Analysis through X-ray diffraction was carried out to confirm the crystalline nature of the particles, and the XRD pattern showed numbers of Braggs reflections that may be indexed on the basis of the face centered cubic structure of silver. A comparison of our XRD spectrum with the standard confirmed that the silver particles formed in our experiments were in the form of nanocrystals, as evidenced by the peaks at $2 \theta$ values of $38.02,43.58$, and 64.32 , and 77.22 corresponding to (111), (200), (220) and (311), respectively Bragg reflections of silver. The assigned peaks at $2 \theta$ values of $14.9 \mathrm{o}$ and $22.72 \mathrm{o}(*)$, Figure 4 may be related to crystalline and amorphous organic phase. The X-ray diffraction results clearly show that the silver nanoparticles formed by the reduction of $\mathrm{Ag}+$ ions by the Olea europaea leaves extract are crystalline in nature. As mentioned in the method section, the silver nanoparticles once formed were repeatedly centrifuged and redispersed in sterile distilled water prior to XRD analysis, thus ruling out the presence of any free biological material that might independently crystallize and giving rise to Bragg reflections. It was found that the average size from XRD data and using Debye-Scherer equation was $10 \pm 1 \mathrm{~nm}$. The presence of structural peaks in XRD patterns and average crystalline size around $10 \mathrm{~nm}$ clearly illustrates that AgNPs synthesized by our green method were nanocrystalline in nature. The XRD pattern of the dried AgNPs obtained by Olea europaea leaves extract is shown in Figure 4. The average particle size of silver nanoparticles synthesized by the present green method calculated using Debye-Scherrer equation[27,28]:
$\mathrm{D}=K \lambda / \beta \cos \theta$

Where $\mathrm{D}=$ the crystallite size of AgNPs particles

$\lambda=$ the wavelength of $\mathrm{x}$-ray source $(0.1541 \mathrm{~nm})$ used in $\mathrm{XRD}$

$\beta=$ the full width at half maximum of the diffraction peak.

$K=$ the Scherrer constant with value from 0.9 to 1 .

$\theta=$ the Bragg angle.

The XRD patterns displayed in this work are in good agreement with the earlier research reported for green synthesis of silver nanoparticles[23].

\subsection{FTIR Analysis of Biosynthesized Silver Nanoparticles}

The FTIR spectrum of biosynthesized silver nanoparticles by the Olea europaea leaves extract, Figure 5 shows a broad and strong band at $3398 \mathrm{~cm}^{-1}$ is due to bounded hydroxyl $(-\mathrm{OH})$ or amine (-NH) groups of Olea europaea leaves extract. A shoulder peak at $1608 \mathrm{~cm}^{-1}$ and $1558 \mathrm{~cm}^{-1}$ indicate the amide I and amide II arise due to carbonyl stretch and $-\mathrm{N}-\mathrm{H}$ stretch vibrations in the amide linkages of the proteins, respectively. The band at $1381 \mathrm{~cm}^{-1}$ corresponds to $\mathrm{C}=\mathrm{C}$ stretching of aromatic amine. FTIR bands of silver nanoparticles, Figure 5 confirms the presence of protein in the silver nanoparticles biosynthesized in this method, which coat covering the silver nanoparticles known as capping proteins. Capping protein stabilizes AgNPs and prevents agglomeration in the medium. FTIR spectroscopy study confirmed that the Olea europaea leaves extract has the ability to perform dual functions of reduction of $\left(\mathrm{Ag}^{+}\right)$to $\left(\mathrm{Ag}^{\circ}\right)$ and stabilization of silver nanoparticles.

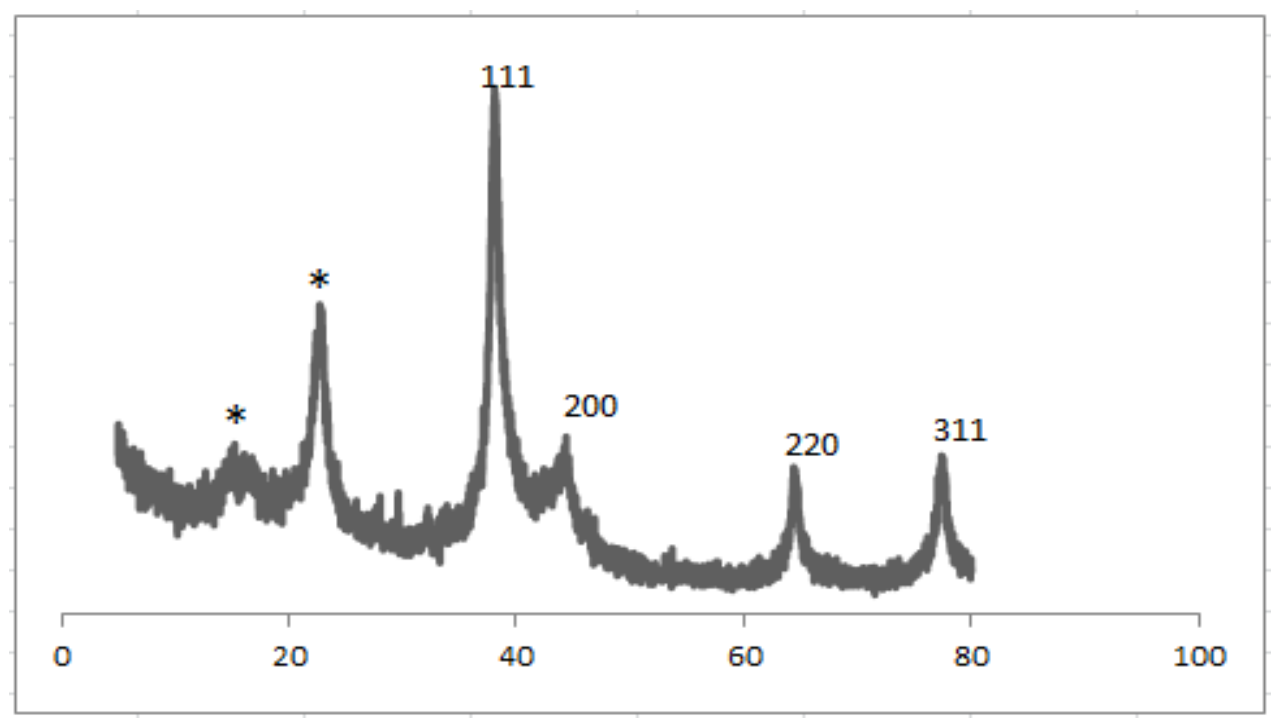

Figure 4. XRD patterns of silver nanoparticles synthesized by treating aqueous $1 \times 10^{-3} \mathrm{M} \mathrm{AgNO}_{3}$ solution with Olea europaea leaves extract 


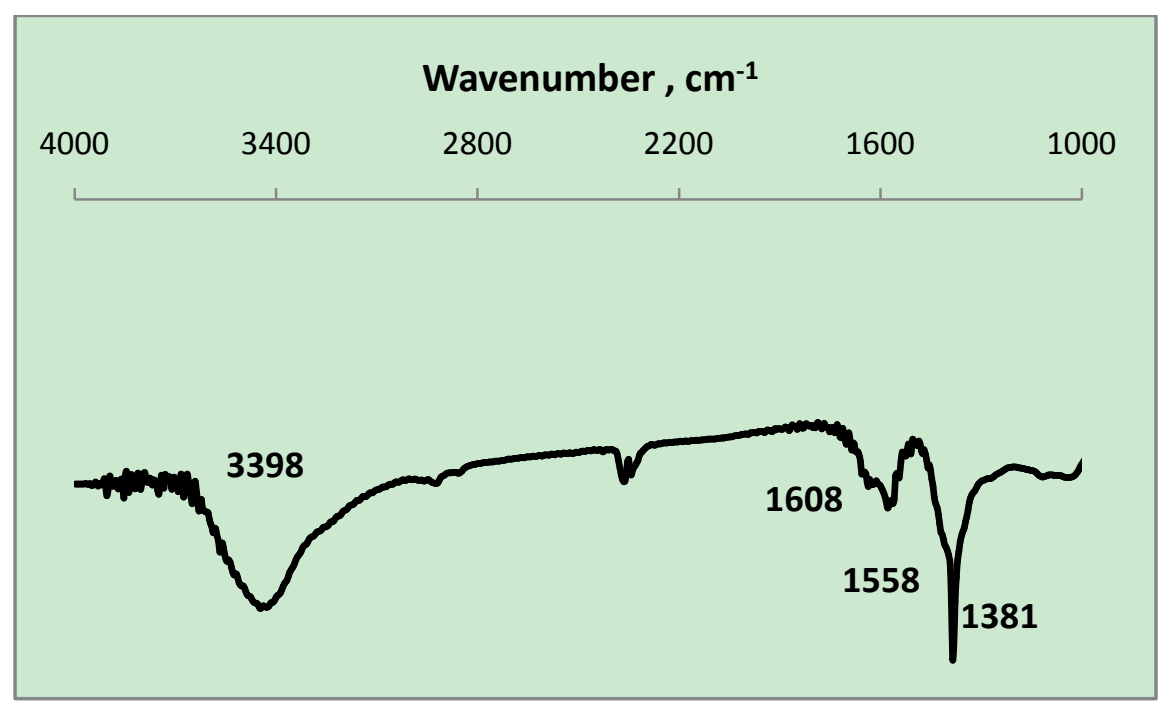

Figure 5. FTIR spectra of silver nanoparticles

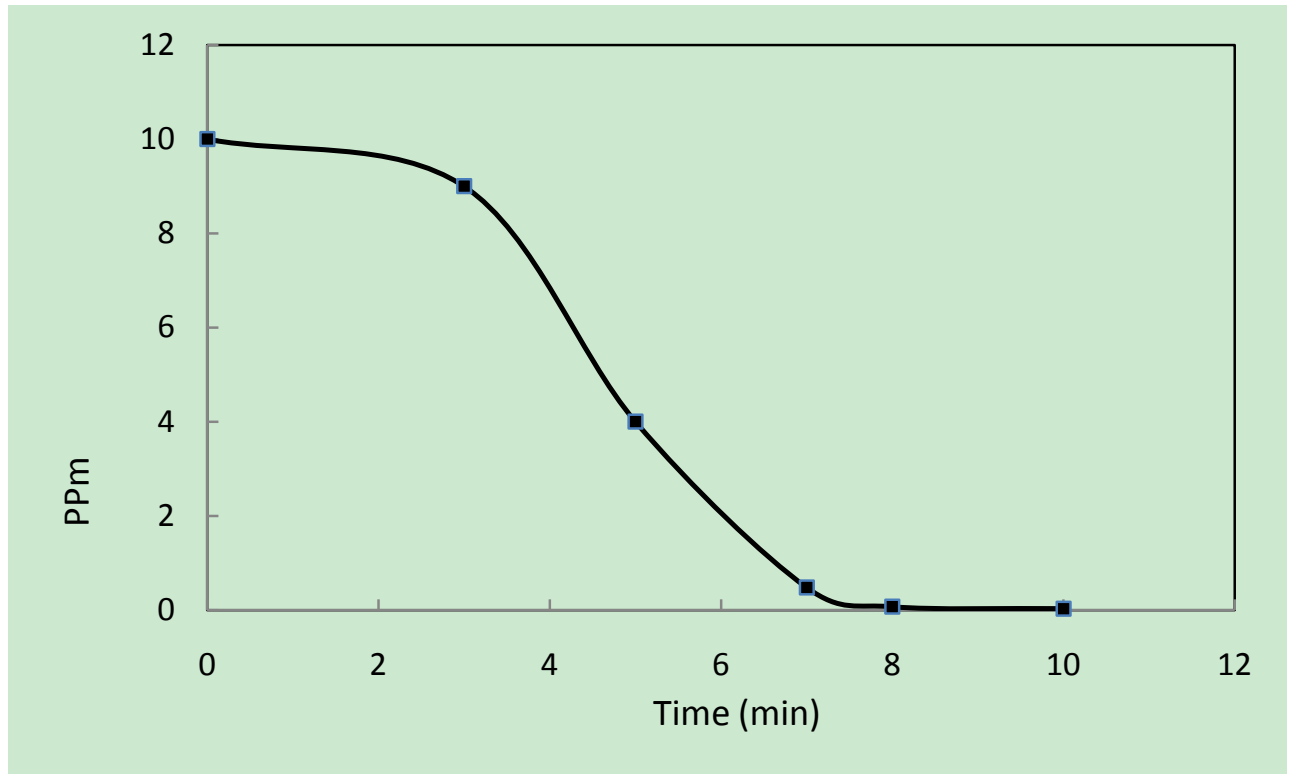

Figure 6. Silver nitrate concentration ( $\mathrm{ppm})$ in reaction mixture with time in minutes

\subsection{Atomic Absorption Spectroscopy (AAS) Analysis}

Silver ions concentration was analyzed by AAS which showed the conversion of $\mathrm{Ag}^{+}$ions into $\mathrm{Ag}$ nanoparticles. Initially, standard solution of $10 \mathrm{ppm}$ of $\mathrm{AgNO}_{3}$ was prepared and analyzed with $\mathrm{AAS}$ at 0 min., Ag ion concentration in the reaction solution, after adding leaf extract of Olea europaea was monitored at different time intervals. The result showed decrease in concentration of $\mathrm{Ag}$ ions 10,4 , and $1 \mathrm{ppm}$ at 0,5 and $10 \mathrm{~min}$, respectively indicating the conversion of $\mathrm{Ag}$ ions into Ag nanoparticles, Figure 6..

\subsection{SEM Analysis of Silver Nanoparticles}

The suspended silver nanoparticles in sterile distilled water were used for scanning electron microscope analysis by fabricating a drop of suspension onto a clean electric stubs and allowing water to completely evaporate. The SEM image of silver nanoparticles synthesized by Olea europaea leaves extract showed cubical and relatively uniform shape of nanoparticles formation with diameter range 10-30 nm, Figure 7.

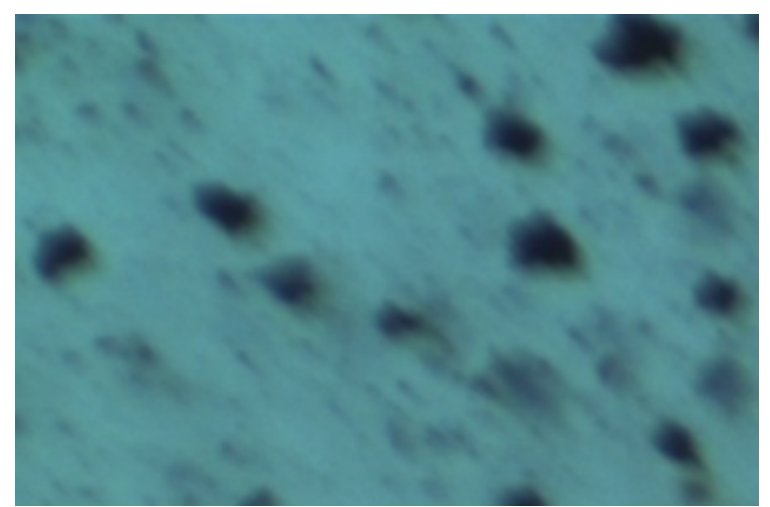

Figure 7. SEM image of silver nanoparticles biosynthesized by Olea europaea leaves extract 


\subsection{Antibacterial Activity Study of Silver Nanoparticles (Ag NPs)}

Biosynthesized silver nanoparticles showed excellent antibacterial activity against Shigella, Listeria and S. aureus, Figure 8-10. The anti-bactericidal activity is estimated by the zone of inhibition. The diameter of the zone of inhibition around the antibiotic disc with silver and without silver nanoparticles against the test strains is shown in Table $\mathbf{1}$. The silver nanoparticles synthesized showed inhibition zone against all the studied bacteria. Maxmium zone of inhibition was found to be $20 \mathrm{~mm}$ in Listeria and minimum of $9.5 \mathrm{~mm}$ in Shegella, Table 1.

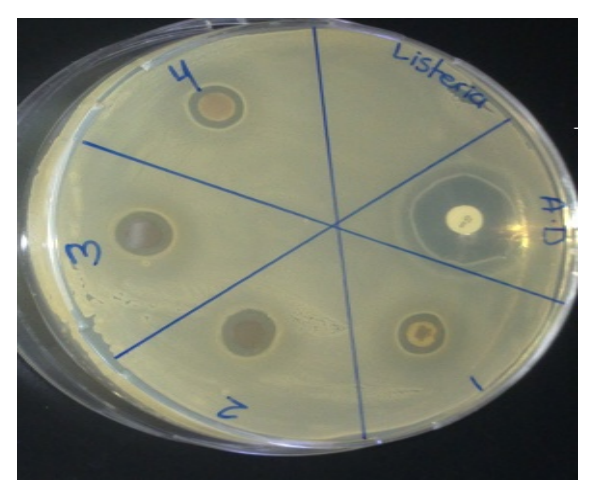

Figure 8. Zone of inhibition against Listeria

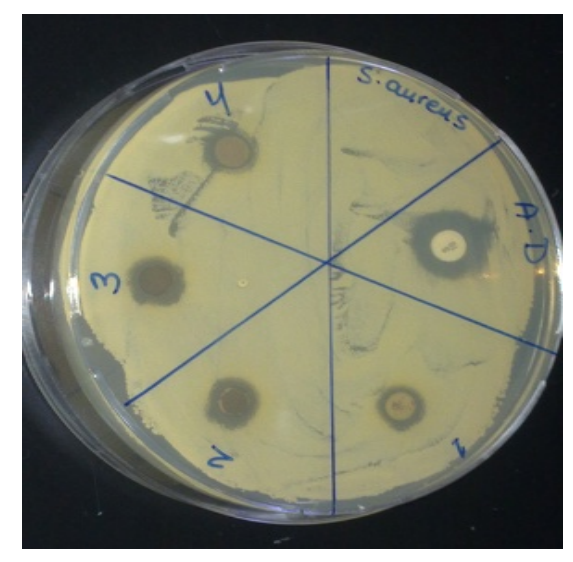

Figure 9. Zone of inhibition against $S$. aureus

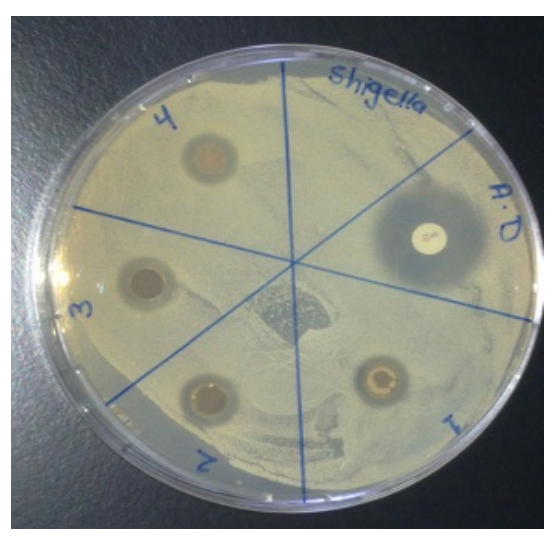

Figure 10. Zone of inhibition against Shigella
Table 1. The antibacterial activity of AgNPs synthesized using Olea europaea leaves extract

\begin{tabular}{ccc}
\hline & \multicolumn{2}{c}{ Zone of inhibition } \\
\cline { 2 - 3 } Name of the bacterial sps & AgNPs & Reference drug \\
\hline Shigella & 9.5 & 17 \\
Staphylococcus aureus & 10 & 19 \\
Listeria monocytogenes & 20 & 20 \\
\hline
\end{tabular}

\section{Conclusions}

This study developed a rapid, eco-friendly and convenient green method for the synthesis of stable silver nanoparticles of average diameter of $10 \pm 1.0 \mathrm{~nm}$ using the aqueous solution of Olea europaea leaves extract. The formation of silver nanoparticles which is confirmed by UV-vis, XRD and SEM, having average mean size of $10 \mathrm{~nm}$ had fcc structure. The antibacterial activity of biologically synthesized silver nanoparticles was evaluated against Listeria monocytogenes, Shigella and Staphylococcus aureus showing effective bactericidal activity.

\section{ACKNOWLEDGEMENTS}

Authors are thankful to Royal Scientific Society and Jordan University for financial support and having given feasibilities to carry out the research work.

\section{REFERENCES}

[1] Vorobyova SA, Lesnikovich AL, Sobal NS (1999). Preparation of silver nanoparticles by interphase reduction. Colloids and Surfaces A - Physicochemical and Engineering Aspects 152: 375-379.

[2] Keki S, Torok J, Deak G (2000). Silver nanoparticles by PAMAM-assisted photochemical reduction of $\mathrm{Ag}^{+}$. J. Colloid Interface Sci.229: 550-553.

[3] Bae CH, Nam SH, S.M. Park SM (2000). Formation of silver nanoparticles by laser ablationof a silver target in $\mathrm{NaCl}$ solution. Appl. Surf. Sci. 197: 628-634

[4] Tan Y, Wang Y, Jiang L (2002). Thiosalicylic acid-functionalized silver nanoparticles, synthesized in one phase system. J. Colloid Interface Sci. 249: 336-345.

[5] Liu YC, Lin LH (2004). New pathway for the synthesis of ultrafine silver nanoparticles from bulk silver substrates in aqueous solutions by sonoelectrochemical methods. Electrochem. Commun 6: 1163-1168.

[6] Yu D-G (2007). Formation of colloidal silver nanoparticles stabilized by $\mathrm{Na}+$-poly(-glutamic acid) silver nitrate complex via chemical reduiction process. Colloids and Surfaces B: Biointerfaces 59: 171-178. 
[7] Saxena A, Tripathi RM, Zafar F, Singh P (2012). Green synthesis of silver nanoparticles using aqueous solution of Ficus benghalensis leaf extract and characterization nof their antibacterial activity. Materials Letters 67: 91-94

[8] Dubey SB, Lahtinen M, Sillanpää M (2010). Green synthesis and characterizations of silver and gold nanoparticles using leaf extract of Rosa rugosa. Colloids and Surfaces A: Physicochemical and Engineering Aspects, 364: 34-41.

[9] Yilmaz M, Turkdemir H, Bayram HE, Cicek A (2011). Biosynthesis of silver nanoparticles using leaves of Stevia rebaudiana. Materials Chemistry and Physics 130: 1195-1202.

[10] Dwivedi AD, K. Gopal K (2010). Biosynthesis of silver and gold nanoparticles using Chenopodium album leaf extract. Colloids and Surfaces A: Physicochemical and Engineering Aspects 369: 27-33

[11] Prasad K.S., Pathak D., Patel A. , Dalwadi, P., Prasad R. , Patel P., Selvara K. (2010). Biogenic synthesis of silver nanoparticles using Nicotiana tobaccum leaf extract and study of their antibacterial effect. African Journal of Biotechnology 10: 8122-8130.

[12] Geethalakshmi R, Sarda DVL (2010). Synthesis of plant-mediated silver nanoparticles using Trianthema decandra extract and evalution of their anti microbial activities. International Journal of Engineering Science and Technology 2: 970-975.

[13] Kaviya S, Santhanalakshml J, Viswanathan B (2011).. Green synthesis of silver nanoparticles using Polyalthia longifolia leaf extract along with D-sorbitol: Study of antibacterial activity Journal of Nanotechnology doi: $10.1155 / 2011 / 1152970$.

[14] Jha JK, Prasad K (2010). Green synthesis of silver nanoparticles using Cycas leaf. Journal of Green Nanotechnology: Physics and Chemistry 1: 110-117.

[15] Song JY, Kim BS (2009). Rapid biological synthesis of silver nanoparticles using plant leaf extracts. Bioprocess Biosyst Eng. 32: 79-84.

[16] Mukunthan KS, Elumalai EK, Patel TN, Murty VR (2011). Catharanthus rosena: a natural source for the synthesis of silver nanoparticles. Asian Pacific Journal of Tropical Biomedicine1: 270-274.

[17] Panda KK, Achary VM, Krishnaveni R, Padhi BK, Sarangi SN, Sahu BB (2011). In vitro biosynthesis and genotoxicity bioassay of silver nanoparticles using plants. Toxicology in Vitro 25: 1097-1105.

[18] Nabikhan A, Kandasamy K, Raj A, Alikunhi NM (2010). Synthesis of antimicrobial silver nanoparticles by callus and leaf extracts from saltmarsh plant, Sesuvium portulacastrum L Colloids and Surfaces B: Biointerfaces, 79: 488-493.

[19] Krishnaraj C, Jagan EG, Rajasekar S, Kalaichelvan PT, Mohan N (2010). Synthesis of silver nanoparticles using Acalypha indica leaf extracts and its antibacterial activity against water borne pathogens. Colloids and Surfaces B: Biointerfaces 76: 50-56.

[20] Sarkar R, Kumbhakar P, Mitra AK (2010). Green synthesis of silver nanoparticles and its optical properties. Digest J. nanomaterials and Biostructures 5: 491-496.

[21] Qiu L, Zhang L, Zhang Q (2007). Green synthesis of silver nanoparticles using Capsicum annuum L extract. Green Chemistry 9: 852-858.

[22] Jacob SJP, Finub JS, Narayanan A (2012). Synthesis of silver nanoparticles using Piper longum leaf extracts and its cytotoxic activity against Hep-2 coll line. Colloids and Surfaces B: Biointerfaces 91: 212-214.

[23] Kouvaris P, Delimittis A, Zaspalis V, Papadopoulos D, Tsipas SA, Michailidis N (2012). Green synthesis and caractérisation of silver nanoparticles produced using Arbutus unedo leaf extract. Materials Letters, 76: 18-20.

[24] Singhal G, Bhavesh R, Kasariya K, Sharma AR, Singh RO (2011). Biosynthesis of silver nanoparticles using Ocimum sanctum (Tulsi) leaf extract and screening its antimicrobial activity. J Nanopart Res 13: 2981-2988.

[25] Awwad AM, Salem NM (2012). Green synthesis of silver nanoparticles by mullberry leaves extract. Nanoscience and Nanotechnology 2 (4):

[26] Perez C, Pauli M, Bazerque P (1990). Antibiotic assay by agar well diffusion method. Acta Biol. Med. Exp. 15: 113-115.

[27] Ahmad N, Sharma S, Alam MdK, Singh VN, Shamsi SF, Mehta BR, Fatma A (2010). Rapid synthesis of silver nanoparticles using dried medicinal plant of basil. Colloids and Surfaces B: Biointerfaces 81: 81-86.

[28] Vidhu VK, Aromal SA, Philip D (2011). Green synthesis of silver nanoparticles using Macrotyloma uniflorum. Spectrochimica Acta Part A: Molecular and Biomolecular Spectroscopy 83: 392-397. 